\title{
Pulmonary function during pregnancy in normal women and in patients with cardiopulmonary disease
}

\author{
KUDDUSI GAZIOGLU, NOLAN L.KALTREIDER, \\ MORTIMER ROSEN, and PAUL N. YU

\begin{abstract}
Cardiology and Pulmonary Disease Units of the Department of Medicine, and the Department of Obstetrics and Gynecology, University of Rochester School of Medicine and Dentistry; and the Medical and Obstetrical Clinics, Strong Memorial Hospital, Rochester, New York
\end{abstract}

\begin{abstract}
Pulmonary function studies were carried out during pregnancy in 8 normal women, in 8 patients with valvular (either mitral or aortic) heart disease, and in 8 patients with chronic pulmonary disease (either emphysema or sarcoidosis). In healthy pregnant women, changes in lung volumes and maximal expiratory flow rates were not significant. Diffusing capacity tended to decrease associated with unchanged pulmonary capillary blood volume. In patients with valvular heart disease, ventilation and oxygen consumption increased toward the term. The patients with mitral valve lesions showed a significant decrease in diffusing capacity with an increase in pulmonary capillary blood volume. In patients wth emphysema, characteristic changes were increasing obstructive functional abnormalities associated with an increase in pulmonary diffusing capacity and pulmonary capillary blood volume. None of these patients, however, had clinical evidence of deterioration of their disease. Patients with sarcoidosis had no appreciable alteration in pulmonary function tests.

The influence of various factors, such as increased ovarian hormones, ventilation-perfusion relationships, intra-abdominal distension, and cardiac haemodynamics, are discussed in relation to the change in pulmonary diffusing capacity and pulmonary capillary blood volume. From the standpoint of pulmonary function studies we think that patients with mitral heart disease and those with pulmonary emphysema tolerate pregnancy less favourably than normal subjects and patients with sarcoidosis.
\end{abstract}

The influence of pregnancy on pulmonary function has been reported by many workers. While some investigators found that pregnancy has little effect on overall respiratory function, others felt that such factors as the gradual abdominal distension, the enlarged breasts, and the inherent circulatory changes do indeed affect the respiratory physiology in the pregnant woman. In the chronically ill patient, it is even more difficult to overlook the progression of respiratory symptoms and the diminution of cardiac reserve during the second half of pregnancy and during the early post-partum period. Part of the problem becomes evident when one notes that there have been only a few reports of serial pulmonary function studies in normal pregnant women as well as in pregnant patients with cardiopulmonary disease.

This paper reports the studies of pulmonary function in 8 normal women and 16 patients with various cardiopulmonary diseases during each of the three trimesters of pregnancy and 10 weeks after delivery. Special attention is focused on changes in pulmonary diffusing capacity and pulmonary capillary blood volume.

\section{METHODS OF STUDY}

In eight normal women and 16 patients, pulmonary function tests were studied during the first (10th week), the second (24th week), and the third (36th week) trimesters of pregnancy and 10 weeks after delivery. The data obtained 10 weeks after delivery were considered as the control values. In all patients radiographs of the chest with shielded abdomen, and electrocardiograms, were taken during each period.

Eight patients had cardiac disease (4 with predominant mitral valve disease and 4 with predominant aortic valve disease) and 8 had pulmonary disease (4 with emphysema and 4 with pulmonary sarcoidosis). In patients with cardiac disease, the diagnosis was made tentatively prior to the pregnancy on the basis of the clinical examination, radiographs of the chest, 
electrocardiogram (ECG), phonocardiogram, left and right heart catheterization, and angiocardiogram. The diagnosis of emphysema was based on clinical, radiological, and repeated physiological evaluations. These patients had typical obstructive functional abnormalities which were irreversible by bronchodilators. We used the criteria as outlined by the committee on diagnostic standards of the American Thoracic Society (1962). None of these patients had symptoms of chronic bronchitis or asthma. In patients with sarcoidosis, chest radiographs showed bilateral reticulonodular or fluffy lesions and hilar enlargement. Scalene lymph node biopsy indicated the presence of non-caseating granulomas. The known duration of the disease varied between one and four years. During the study there were no changes in symptomatology or radiological findings.

Pulmonary function tests included estimates of subdivisions of the lung volume by the method of Meneely and Kaltreider (1949), minute ventilation (MV), oxygen uptake $\left(\mathrm{V}_{2}\right)$, ventilatory equivalent for oxygen $\left(\mathrm{VEO}_{2}\right)$, simultaneous measurements of maximum expiratory flow-volume (MEFV), and forced vital capacity (FVC) curves, as described by Gazioglu, Condemi, Kaltreider, and Yu (1968), and determination of breath-holding carbon monoxide diffusing capacity $\left(\mathrm{D}_{\mathrm{L}}\right)$, pulmonary membrane diffusing capacity ( $\mathrm{D}_{\mathrm{M}}$ ), and pulmonary capillary blood volume (V) of Forster, Roughton, Cander, Briscoe, and Kreuser (1957). A comparison of subdivisions of lung volumes, MEFV, and FVC in each period was made by using the absolute values (Gaensler, Patton, Verstraeten, and Badger, 1953; Gaensler and Wright, 1966), while the values of $\mathrm{MV}, \dot{\mathrm{V}} \mathrm{O}_{2}, \mathrm{D}_{\mathrm{L}}, \mathrm{D}_{\mathrm{M}}$, and $V_{0}$ were adjusted according to the body surface area (Bader, Bader, Rose, and Braunwald, 1955 ; Forster et al., 1957; McNeill, Rankin, and Forster, 1958 ; Gazioglu and $Y u, 1967)$. $V_{0}$ was corrected for a normal blood haemoglobin of $14.9 \mathrm{~g} . / 100 \mathrm{ml}$. by measuring the subject's haemoglobin at each study. All studies were carried out in the sitting position except for MEFV and FVC measurements which were performed in the standing position.
RESULTS

The physical characteristics of the normal subjects and of the patients with cardiopulmonary disease are presented in Table $I$. In all patients, the severity of the disease before and following pregnancy was relatively mild without interfering with their usual household activities. In one patient

T A B LE I

PHYSICAL CHARACTERISTICS OF PREGNANT WOMEN

\begin{tabular}{|c|c|c|c|c|}
\hline $\begin{array}{l}\text { Sub- } \\
\text { ject } \\
\text { No. }\end{array}$ & Diagnosis & $\begin{array}{l}\text { Age } \\
(\mathrm{yr})\end{array}$ & $\begin{array}{l}\text { Height } \\
\text { (cm.) }\end{array}$ & $\begin{array}{c}\text { BSA } \\
\left(\mathrm{m} .{ }^{2}\right)\end{array}$ \\
\hline $\begin{array}{r}1-8 \\
9 \\
10 \\
11 \\
12 \\
13 \\
14 \\
15 \\
16 \\
17 \\
18 \\
19 \\
20 \\
21 \\
22 \\
23 \\
24\end{array}$ & $\begin{array}{l}\text { Normal subjects } \\
\text { Mitral valve disease } \\
\text { Mitral valve disease } \\
\text { Mitral valve disease } \\
\text { Mitral valve disease } \\
\text { Aortic valve disease } \\
\text { Aortic valve disease } \\
\text { Aortic valve disease } \\
\text { Aortic vavle disease } \\
\text { Emphysema } \\
\text { Emphysema } \\
\text { Emphysema } \\
\text { Emphysema } \\
\text { Pulmonary } \\
\text { sarcoidosis } \\
\text { Pulmonary } \\
\text { sarcoidosis } \\
\text { Pulmonary } \\
\text { sarcoidosis } \\
\text { Pulmonary } \\
\text { sarcoidosis }\end{array}$ & $\begin{array}{lc}\text { Range } & 18-29 \\
\text { Mean } & 24 \\
& 23 \\
24 \\
22 \\
32 \\
29 \\
25 \\
34 \\
27 \\
34 \\
27 \\
30 \\
36 \\
27 \\
\\
33 \\
\\
22 \\
\\
21\end{array}$ & $\begin{array}{c}153-170 \\
164 \\
156 \\
159 \\
162 \\
161 \\
166 \\
170 \\
174 \\
163 \\
158 \\
156 \\
165 \\
167 \\
161 \\
166 \\
165 \\
168\end{array}$ & $\begin{array}{c}1.46-1 \cdot 84 \\
1.62 \\
1.51 \\
1.60 \\
1.63 \\
1.57 \\
1.67 \\
1.79 \\
1.82 \\
1.70 \\
1.58 \\
1.49 \\
1.70 \\
1.67 \\
1.50 \\
1.69 \\
1.70 \\
1.67\end{array}$ \\
\hline
\end{tabular}

with mitral valve disease (patient 9) some increase in fatigue, the presence of ankle swelling, and cardiac enlargement on chest radiographs were noted during the third trimester of pregnancy. In other patients, there was no clinical, radiological or ECG evidence suggestive of progression or improvement of their disease during and after pregnancy.

Subdivisions of lung volumes in the pregnant women are summarized in Table II. In normal

T A B L E II

SUBDIVISIONS OF LUNG VOLUMES IN PREGNANT WOMEN

\begin{tabular}{|c|c|c|c|c|c|c|c|c|c|c|c|c|c|c|c|c|}
\hline \multirow[b]{3}{*}{ Weeks } & \multicolumn{4}{|c|}{ Vital Capacity (litres) } & \multicolumn{4}{|c|}{ Inspiratory Capacity (litres) } & \multicolumn{4}{|c|}{$\begin{array}{l}\text { Expiratory Reserve } \\
\text { Volume (litres) }\end{array}$} & \multicolumn{4}{|c|}{ Residual Volume (litres) } \\
\hline & \multicolumn{3}{|c|}{ Pregnancy } & \multirow{2}{*}{$\frac{\begin{array}{c}\text { Post } \\
\text { Partum }\end{array}}{10}$} & \multicolumn{3}{|c|}{ Pregnancy } & \multirow{2}{*}{$\begin{array}{c}\begin{array}{c}\text { Post } \\
\text { Partum }\end{array} \\
10\end{array}$} & \multicolumn{3}{|c|}{ Pregnancy } & \multirow{2}{*}{$\begin{array}{c}\begin{array}{c}\text { Post } \\
\text { Partum }\end{array} \\
10\end{array}$} & \multicolumn{3}{|c|}{ Pregnancy } & \multirow{2}{*}{\begin{tabular}{|c|}
$\begin{array}{c}\text { Post } \\
\text { Partum }\end{array}$ \\
10 \\
\end{tabular}} \\
\hline & 10 & 24 & 36 & & 10 & 24 & 36 & & 10 & 24 & 36 & & 10 & 24 & 36 & \\
\hline Normal subjects .. & $3 \cdot 8$ & 3.9 & $4 \cdot 1$ & $3 \cdot 8$ & $2 \cdot 6$ & $2 \cdot 7$ & 2.9 & $2 \cdot 5$ & $1 \cdot 2$ & $1 \cdot 2$ & $1 \cdot 2$ & $1 \cdot 3$ & $1 \cdot 2$ & $1 \cdot 1$ & 1.0 & $1 \cdot 2$ \\
\hline \multirow{3}{*}{$\begin{array}{c}\text { Patients with } \\
\text { Mitral valve } \\
\text { disease... } \\
\text { Aortic valve } \\
\text { disease... } \\
\text { Emphysema } \\
\text { Pulmonary } \\
\text { sarcoidosis }\end{array}$} & $2 \cdot 9$ & $2 \cdot 7$ & $2 \cdot 6$ & $3 \cdot 1$ & $2 \cdot 0$ & 1.9 & $2 \cdot 0$ & $2 \cdot 1$ & 0.9 & $0 \cdot 8$ & 0.6 & $1 \cdot 0$ & $1 \cdot 3$ & $1 \cdot 2$ & $1 \cdot 1$ & $1 \cdot 4$ \\
\hline & $\begin{array}{l}3 \cdot 7 \\
2 \cdot 8\end{array}$ & $\begin{array}{l}3 \cdot 8 \\
3 \cdot 0\end{array}$ & $\begin{array}{l}3 \cdot 6 \\
3 \cdot 0\end{array}$ & $\begin{array}{l}3.7 \\
2 \cdot 8\end{array}$ & $\begin{array}{l}2.7 \\
1.6\end{array}$ & $\begin{array}{l}2 \cdot 7 \\
1.9\end{array}$ & $\begin{array}{l}2.6 \\
1.9\end{array}$ & $\begin{array}{l}2 \cdot 6 \\
1 \cdot 6\end{array}$ & $\begin{array}{l}1 \cdot 0 \\
1 \cdot 2\end{array}$ & $\begin{array}{l}1 \cdot 1 \\
1 \cdot 1\end{array}$ & $\begin{array}{l}1 \cdot 0 \\
1 \cdot 1\end{array}$ & $\begin{array}{l}1 \cdot 1 \\
1 \cdot 2\end{array}$ & $\begin{array}{l}0 \cdot 8 \\
1 \cdot 7\end{array}$ & $\begin{array}{l}1.0 \\
1.9\end{array}$ & $\begin{array}{l}0.9 \\
2 \cdot 1\end{array}$ & $\begin{array}{l}0.8 \\
1.6\end{array}$ \\
\hline & $2 \cdot 3$ & $2 \cdot 2$ & $2 \cdot 2$ & $2 \cdot 4$ & 1.4 & 1.4 & 1.5 & 1.5 & 0.9 & 0.8 & 0.7 & 0.9 & 0.8 & 0.7 & 0.7 & 0.7 \\
\hline
\end{tabular}




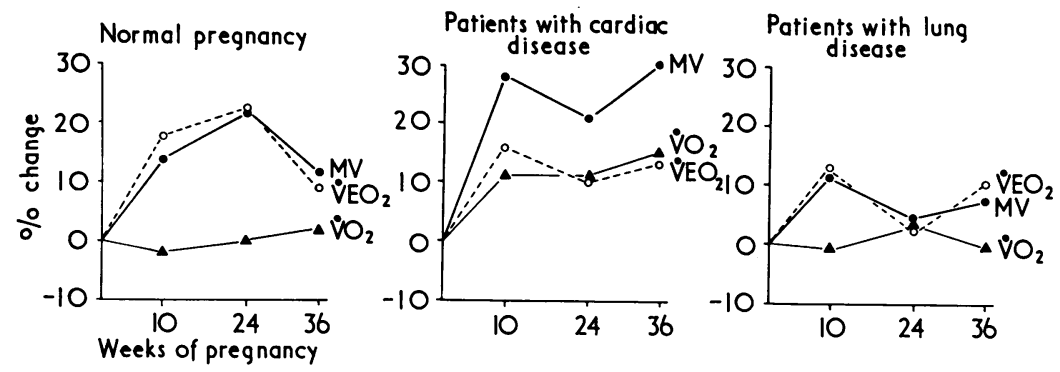

FIG. 1. Changes in minute ventilation $(M V)$, oxygen uptake $\left(\dot{V} O_{2}\right)$ and ventilatory equivalent for oxygen $\left(\dot{V} \mathrm{EO}_{2}\right)$ throughout the pregnancy. For comparison, the values obtained 10 weeks after delivery were considered as controls.

subjects, the vital capacity (VC) increased 0.3 litre toward the term, mainly by an average increase of 0.4 litre in inspiratory capacity (IC). In contrast, the average expiratory reserve volume (ERV) decreased $0 \cdot 1$ litre and the residual volume (RV) decreased 0.2 litre. The RV/TLC of these subjects remained almost the same because of opposite directional change in VC and RV.

In patients with predominant mitral valve disease, VC decreased 0.5 litre, ERV decreased 0.4 litre and RV decreased 0.3 litre during pregnancy. In patients with emphysema, total lung capacity (TLC) increased from 4.4 litres (post-partum) to $5 \cdot 1$ litres at 36 weeks, and the RV/TLC increased slightly as a result of more increase in $\mathrm{RV}(0.5$ litre) than that in VC $(0.2$ litre). In patients with predominant aortic valve disease and in those with sarcoidosis, no appreciable change of lung volumes was observed.

Percentage changes of $\mathrm{MV}, \mathrm{VO}_{2}$, and $\mathrm{VEO}_{2}$ in pregnant women are depicted in Fig. 1. In normal subjects, maximum changes of $\mathrm{MV}$ and $\mathrm{VEO}_{2}$ were observed in the 24th week of pregnancy. Increased MV was due to an increased tidal volume (TV), since respiratory rate (RR) remained unchanged. There was an overall $8 \%$ increase in $\mathrm{VO}_{2}$ toward the term. These changes were not significant when they were expressed per body surface area (BSA).

In patients with valvular heart disease, MV and $\mathrm{VO}_{2}$ increased more significantly than that observed in normal pregnant women. As a result of more increase in $\mathrm{MV}$ than in $\mathrm{VO}_{2}$, an elevation of $\dot{\mathrm{VEO}}_{2}$ was also observed. In patients with emphysema and in those with sarcoidosis, the changes of $\mathrm{MV}$ and $\mathrm{VO}_{2}$, however, were insig. nificant.

The results of analysis of MEFV and FVC curves in pregnant women are illustrated in Fig. 2.

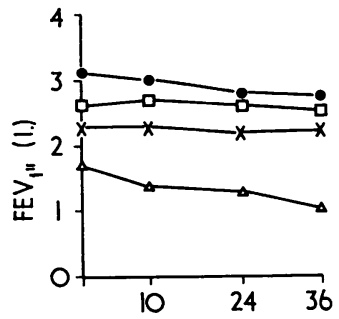

- Normal subjects

a Patients with volvular heart disease

$x$ Patients with pulmonary sorcoidosis

$\Delta$ Patients with emphysema
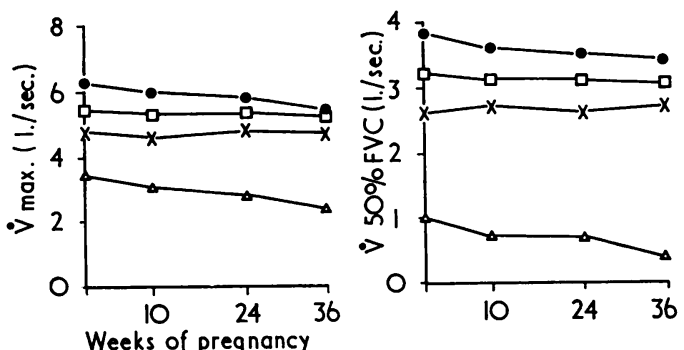

FIG. 2. Changes in forced vital capacity (FVC) and maximum expiratory flow volume (MEFV) measurements in pregnant women. For comparison, the values obtained 10 weeks after delivery were considered as controls. $\dot{V}_{\max }$ = peak flow; $F E V_{1 "}=$ mean flow in the first second of $F V C ; \dot{V} 50 \% F V C=$ flow rate at $50 \%$ of $F V C$.

In normal subjects, in patients with cardiac disease, and in those with pulmonary sarcoidosis, no significant change in MEFV and FVC was observed during pregnancy. Three patients with emphysema had no clinical evidence of deterioration of their disease during the course of their pregnancy, nevertheless some progression of the obstructive abnormality was demonstrated in MEFV and FVC curves. The remaining patient (patient 18) in this group showed no appreciable change in 
T A B L E I I I

PULMONARY DIFFUSING CAPACITY $\left(D_{L}\right)$, DIFFUSING CAPACITY OF MEMBRANE (DM) AND PULMONARY CAPILLARY BLOOD VOLUME (V $\mathrm{V}_{\mathrm{c}}$ IN PREGNANT WOMEN

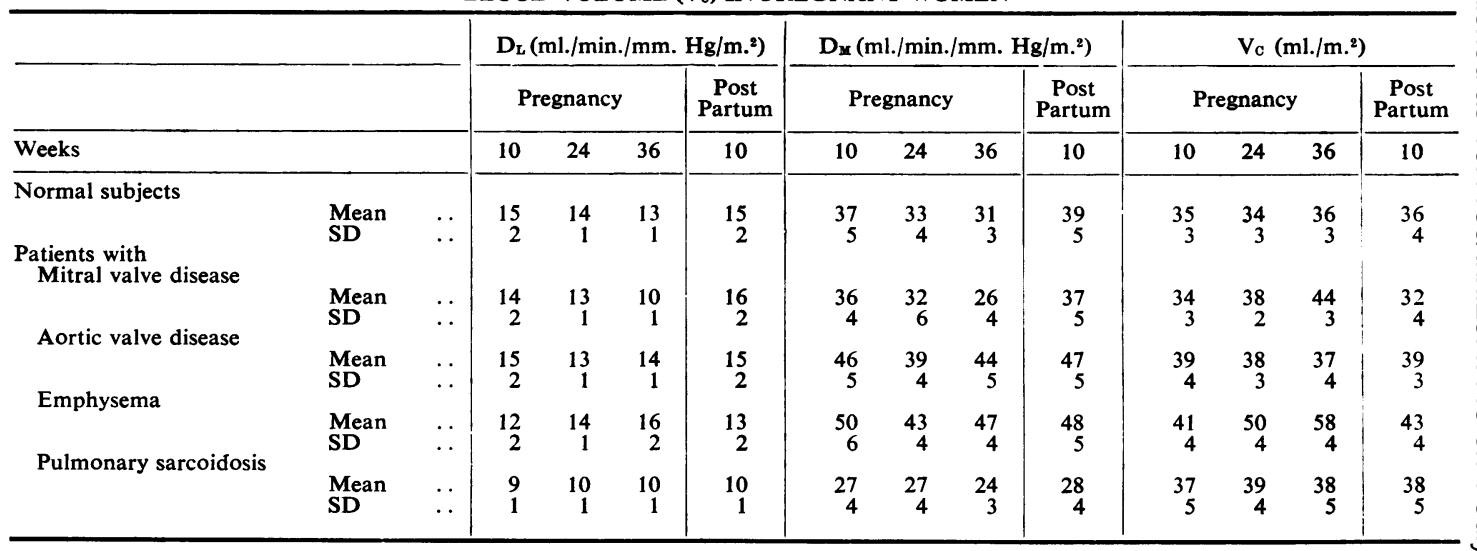

her mild obstructive abnormality. She had a history of asthma in childhood.

A slight decrease in $D_{L}$ was observed in six normal pregnant women, but there was no change in $D_{L}$ in the remaining two. However, changes of mean values were found to be statistically insignificant (Table III). $D_{M}$ decreased slightly in the majority of normal pregnant subjects, while $\mathrm{V}_{\mathrm{c}}$ remained unchanged.

In patients with mitral valve disease, although $D_{L}$ and $D_{M}$ were reduced, $V_{c}$ increased progressively during pregnancy. In patients with aortic valve disease, there were no significant changes in any one of the three parameters.

In the emphysema group, there was a steady increase in $D_{L}$ and $V_{c}$ associated with unchanged $D_{M}$. Patients with pulmonary sarcoidosis had the lowest $D_{L}$ and $D_{M}$ of the entire group which remained unchanged throughout pregnancy. Their $\mathrm{V}_{\mathrm{o}}$ remained normal during pregnancy.

\section{DISCUSSION}

In normal pregnant women, changes in lung volume profile were characterized by a progressive increase in VC and IC on the one hand and by some decrease in ERV and RV on the other. These changes, however, are not statistically significant and are similar to those previously reported by $\mathrm{Gaensler}$ and his associates $(1953,1966)$.

Although there was an increase in absolute values of $\mathrm{MV}$ and $\mathrm{VO}_{2}$ during pregnancy, the values expressed per body surface area were found to be statistically insignificant.

Gaensler and his co-workers $(1953,1966)$ found no appreciable changes in maximal breathing capacity during late pregnancy in normal women. The studies of Rubin, Russo, and Goucher (1956) and Gee, Packer, Millen, and Robin (1967) indicated a decrease of total pulmonary resistance during pregnancy in normal women. Gee and his associates (1967) observed that a decrease in airway resistance was the major factor for reduction of total pulmonary resistance during $\overrightarrow{\overrightarrow{0}}$ pregnancy. In contrast, Krumholz, Echt, and Ross (1964) observed some increase in airway resistance in the last trimester of normal pregnancy, although the change was found to be statistically not significant. Likewise, analysis of MEFV and FVC curves obtained in the present study suggests no significant changes of airway resistance during pregnancy of normal women.

Krumholz et al. (1964) reported no difference in $D_{L}, D_{M}$, and $V_{c}$ in the first (14 weeks) and late (27 weeks) periods of pregnancy in normal women. In our studies $D_{L}$ and $D_{M}$ tended to decrease toward the last trimester of pregnancy, whereas $\mathrm{V}_{\mathrm{c}}$ remained unchanged throughout. We $\mathrm{N}$ found no correlation between a decrease in either $D_{L}$ or $D_{M}$ and the changes in lung volumes and ventilation. A lowered haemoglobin level may $\mathrm{N}$ contribute to the corresponding decrease in total diffusing capacity as previously reported by 0 Rankin, McNeill, and Forster (1961). However, there was no correlation between $D_{L}$ and the haemoglobin level, which showed a slight decrease toward the term in some subjects.

Brown studied the oestrogen excretion of pregnant women (1959) and found that ovarian hormones increase during gestation and fall off abruptly after delivery. Pecora, Putnam, and Baum (1963) observed that intravenous oestrogens 
given to both male and female human subjects produced a statistically significant decrease in the $D_{L}$ as measured by the single breath method. They postulated that an injection of oestrogen caused an increase in acid mucopolysaccharides in the alveolar capillary zone which would tend to decrease $D_{L}$.

Rankin, McNeill, and Forster (1960) reported a correlation between the decrease in $D_{L}$ and the reduction of alveolar $\mathrm{CO}_{2}$ tension in non-pregnant subjects. In pregnancy, a lowered alveolar and arterial $\mathrm{CO}_{2}$ tension and a reduced blood plasma $\mathrm{CO}_{2}$ content and combining power have been repeatedly demonstrated by Hellegers, Metcalfe, Huckabee, Meschia, Prystowky, and Barron (1959) and Prowse and Gaensler (1965). These changes are similar to those observed after acclimatization to high altitude and to those seen in patients with 'alveolar capillary block' syndrome. The importance of the ventilation-perfusion relationships in the gas exchange mechanism of the lung have been delineated by Cadigan, Marks, Ellicott, Jones, and Gaensler (1961), Apthorp and Marshall (1961), and Hatzfeld, Wiener, and Briscoe (1967). It is possible that demands of the foetus and hormonal and mechanical effects of pregnancy may change the ventilation-perfusion ratio of the lung. Holley, Milic-Emili, Becklake, and Bates (1967), employing a radioactive xenon technique, found that limitation of diaphragmatic excursion in obese subjects results in regional ventilation-perfusion abnormalities in the lower lung fields. This situation is somewhat similar to that found in pregnant women in terms of increased intra-abdominal distension and elevation of the diaphragm. Nevertheless, the change in $D_{L}$ is statistically insignificant and interestingly hypervolaemia of pregnancy does not affect $V_{c}$ in normal women.

In contrast to the normal group, pregnant patients with mitral valve disease had a progressive reduction of VC. Their ERV and RV decreased and $\mathrm{MV}$ and $\mathrm{VO}_{2}$ increased much more significantly than the corresponding parameters observed in normal pregnant women. However, there was no appreciable change in either MEFV or FVC. A significant decrease in $D_{L}$ and a significant increase in $V_{c}$ were observed $(P<0.05)$. Cadigan et al. (1961) reported a direct relationship between $D_{L}$ and alveolar volume. In the present study, however, we found no close correlation between reduced $D_{L}$ and related alveolar volume. It is true that reduced alveolar volume in some patients is considered as one of the contributory factors in decreasing $D_{L}$. Palmer, Gee, Mills, and Bates (1963) and Yu (1969) suggested that changes in cardiodynamics alone or combined with the aforementioned factors could reduce $D_{L}$. In some nonpregnant patients with a mitral valve lesion an increase in $\mathrm{V}_{\mathrm{c}}$ as a result of pulmonary vascular congestion was reported by Palmer et al. (1963) and by Gazioglu and $Y u$ (1967) and $Y u$ (1969). In normal pregnant women $\mathrm{V}_{\mathrm{c}}$ is maintained at a fairly constant level despite increased blood volume. In contrast, a further increase in $V_{c}$ was observed in pregnant women with mitral valve disease. Hypervolaemia in these patients not only augments the pulmonary blood capillary volume but also produces a disproportionate rise in the pulmonary vascular pressure. These changes may explain in part why some patients with mitral stenosis may develop acute pulmonary oedema during the later stage of pregnancy. Pregnant women with aortic valve disease showed no changes in parameters of pulmonary function tests except for their $\mathrm{MV}$ and $\mathrm{VO}_{2}$, which were more appreciably increased than those observed in normal subjects.

In patients with emphysema, there was a progressive decrease in MEFV and FVC and a progressive increase in $\mathrm{D}_{\mathrm{L}}$ and $\mathrm{V}_{\mathrm{c}}$. Rankin et al. (1960), Cadigan et al. (1961), Apthorp and Marshall (1961), and Hatzfeld et al. (1967) pointed out that uneven distribution of inspired gas in proportion to blood flow may often lead to an over-estimation of $D_{L}$ by the single-breath method in patients with obstructed airways. An increasing obstructive process during pregnancy in these patients and further disturbances in ventilation-perfusion relations may thus result in an over-estimation of $D_{L}$ and $V_{c}$. On the other hand, Forster and his colleagues (1957), Krumholz et al. (1964), and $\mathrm{Yu}$ (1969) indicated that, in a given individual patient, the values are quite reproducible and that the results of serial measurements should provide useful information concerning the status of the pulmonary capillary bed. Therefore, $i t$ is possible that true $D_{L}$ and $V_{c}$ do increase in these subjects. We are not certain as to the exact mechanism of these changes as far as this study is concerned. Helpful information may be obtained by haemodynamic examination during pregnancy in emphysematous women.

Unaltered parameters of pulmonary function during pregnancy in patients with sarcoidosis suggest that these patients can tolerate pregnancy better than those with either cardiac disease or emphysema.

The authors are grateful to Dr. Deji Femi-Pearse, formerly of the Cardiopulmonary Unit and presently at the Lagos Medical School, Lagos, Nigeria, for his 
interest and assistance. The technical assistance of Mr. Edward Mahoney and the secretarial help of Mrs. Edith Witt are appreciated.

This work was supported by grants-in-aid from the U.S. Public Health Service (HE-03966, HE-5500, and $\mathrm{OH}-00209)$ and the Genesee Valley Heart Association.

\section{REFERENCES}

American Thoracic Society (1962). Committee on Diagnostic Standards for Nontuberculous Diseases: chronic bronchitis, asthma and pulmonary emphysema. Amer. Rev. resp. Dis., 85, 762 .

Apthorp, G. H., and Marshall, R. (1961). Pulmonary diffusing capacity: a comparison of breath-holding and steady state methods using carbon monoxide. J. clin. Invest., 40, 1775 .

Bader, R. A., Bader, M. E., Rose, D. J., and Braunwald, E. (1955). Hemodynamics at rest and during exercise in normal pregnancy as studied by cardiac catheterization. J. clin. Invest., 34, 1524

Brown, J. B. (1959). Estrogen excretion of the pregnant woman. In Recent Progress in the Endocrinology of Reproduction, p. 335 Edited by Lloyd, C. W. Academic Press, New York.

Cadigan, J. B., Marks, A., Ellicott, M. F., Jones, R. H., and Gaensler, E. A. (1961). An analysis of factors affecting the measuremen of pulmonary diffusing capacity by the single breath method. J. clin. Invest., 40, 1495.

Forster, R. E., Roughton, F. J. W., Cander, L., Briscoe, W. A., and Kreuser, F. (1957). Apparent pulmonary diffusing capacity for $\mathrm{CO}$ at varying alveolar $\mathrm{O}_{2}$ tension. J. appl. Physiol., 11, 277.

Gaensler, E. A., Patton, W. E., Verstraeten, J. M., and Badger, T. L. (1953). Pulmonary function in pregnancy. Amer. Rev. Tuberc., 67, 779.

- and Wright, G. W. (1966). Evaluation of respiratory impairment. Arch. environm. Hlth, 12, 146.

Gazioglu, K., Condemi, J., Kaltreider, N. L., and Yu, P. N. (1968). Study of forced vital capacity and maximal expiratory flowvolume curves in obstructive lung disease. Amer. Rev. resp. Dis., 98, 857. and Yu, P. N. (1967). Pulmonary blood volume and pulmonary $35,701$.

Gee, J. B. L., Packer, B. S. Millen, J. E, and Robin, E. D. (1967) Pulmonary mechanics during pregnancy. J. clin. Invest., 46, 945.

Hatzfeld, C., Wiener, F., and Briscoe, W. A. (1967). Effects of uneven ventilation-diffusing ratios on pulmonary diffusing capacity in disease. J. appl. Physiol., 23, 1.

Hellegers, A., Metcalfe, J., Huckabee, W., Meschia, G., Prystowky, @ H., and Barron, D. (1959). The alveolar $\mathrm{pCO}_{2}$ and $\mathrm{pO}_{2}$ in pregnant $\mathrm{os}$ and non-pregnant women at altitude. J. clin. Invest., 38, 1010.

Holley, H. S., Milic-Emili, J., Becklake, M. R., and Bates, D. V. (1967). Regional distribution of pulmonary ventilation and perfusion in obesity. J. clin. Invest., 46, 475.

Krumholz, R. A., Echt, C. R., and Ross, J. C. (1964). Pulmonary diffusing capacity, capillary blood volume, lung volumes and mechanics of ventilation in early and late pregnancy. J. Lab. clin. Med., 63, 648 .

McNeill, R. S., Rankin, J., and Forster, R. E. (1958). The diffusing $N$ capacity of the pulmonary membrane and the pulmonary capillary blood volume in cardiopulmonary disease. Clin. Sci., $17,465$.

Meneely, G. R., and Kaltreider, N. L. (1949). The volume of the lung $\mathrm{G}$ determined by helium dilution. Description of the method and comparison with other procedures. J. clin. Invest., 28, 129.

Palmer, W. H., Gee, J. B. L., Mills, F. C., and Bates, D. V. (1963). Disturbances of pulmonary function in mitral valve disease. Canad. med. Ass. J., 89, 744.

Pecora, L. J., Putnam, L. R., and Baum, G. L. (1963). Effects of intravenous estrogens on pulmonary diffusing capacity. Amer. J. med. Sci., 246, 48 .

Prowse, C. M., and Gaensler, E. A. (1965). Respiratory and acid-base changes during pregnancy. Anesthesiology, 26, 381.

Rankin, J., McNeill, R. S., and Forster, R. E. (1960). Influence of increased alveolar carbon dioxide tension on pulmonary diffusing capacity for CO in man. J. appl. Physiol., 15, 543.

(1961). The effect of anemia on the alveolar-capillary exchange of carbon monoxide in man. J. clin. Invest., 40, 1323.

Rubin, A., Russo, N., and Goucher, D. (1956). The effect of pregnancy upon pulmonary function in normal women. Amer. J. Obstet. Gynec., 72, 963.

Yu, P. N. (1969). Pulmonary Blood Volume in Health and Disease. Lea and Febiger, Philadelphia. 